\title{
O "Inventário de perdas da perda de uma vida": K.: Relatos de uma busca, de Bernardo Kucinski, em Partilhas $^{1}$
}

Luan Erick Lima Sanches ${ }^{2}$

Resumo: No período entre 1964-85, ocorre no Brasil a Ditadura Civil-Militar. Um golpe cujas consequências fraturaram uma população inteira de formas variadas. Ana Rosa Kucinski foi uma destas, desaparecida em 1974 junto ao seu marido Wilson Silva. O pai, Majer Kucinski, desde então a procura e essa busca foi narrada no romance de Bernardo Kucinski, K.: Relatos de uma busca. O presente artigo pretende analisar esta obra tendo como condutor a partilha, conceito utilizado por Jacques Ranciére que reflete na perspectiva memorialística do romance. No estudo, me auxilia a teoria do testemunho, seguindo a sua metodologia, portanto: entender a memória traumática e suas funções na narrativa; e as conexões com Agamben, Derrida e Maturana que corroboram para um melhor entendimento da intraduzibilidade das experiências-limite.

Palavras-chave: Partilha, Memória, Testemunho, Ditadura Brasileira, Bernardo Kucinski.

Abstract: In the period between 1964-85, the Civil-Military Dictatorship takes place in Brazil. A coup whose consequences fractured an entire population in a variety of ways. Ana Rosa Kucinski was one of these, who disappeared in 1974 with her husband Wilson Silva. Her father Majer Kucinski has since searched for her, and this search has been told in Bernardo Kucinski's novel, K.: Relatos de uma busca. The present article intends to analyze this work having as conductor the sharing, concept used by Jacques Ranciére that reflects in the memorialistic perspective of the novel. In the study, the theory of the testimony helps, following its methodology, therefore: to understand the traumatic memory and its functions in the narrative; and the connections with Agamben, Derrida and Maturana that corroborate for a better understanding of the untranslatability of limit-experiences.

${ }^{1}$ Este trabalho é parte de um estudo iniciado em projeto de iniciação científica no grupo de pesquisa Narrares - Narrativas de Resistência, orientado pela Professora Dra. Tânia Maria Pereira Sarmento-Pantoja (FALE/PPGL/ILC/UFPA). Aqui está apresentado parcialmente.

${ }^{2}$ Graduando em História - Licenciatura pela UFPA, bolsista de Iniciação Científica PIBIC/CAPES.

Revista Vernáculo n. ${ }^{\circ} 42$ - segundo semestre /2018

ISSN 2317-4021 
Key-words: Share, Memory, Testimony, Brazilian Dictatorship, Bernardo Kucinski.

\section{A abertura $^{3}$}

A obra de Bernardo Kucinski tem ganhado bastante repercussão desde o seu lançamento. Publicada originalmente em 2011, no Brasil, já foi traduzida para o alemão, espanhol, italiano e hebraico, entre outros idiomas, além de ganhar alguns prêmios como o São Paulo de Literatura (2012). O autor é jornalista, escritor e ex-professor da Universidade de São Paulo. Majer Kucinski é o protagonista em K.: Relatos de uma busca e procura a filha desaparecida pelo Estado brasileiro durante o período ditatorial (1964-1984). Nesta desaparição é que se concentra o autor e na busca, tratada pelo inventário de traumas de Majer - inventário aqui entendido pela lógica de sua etimologia, bem como pelo direito das sucessões. E deste arrolamento se descobre toda uma vida da filha desaparecida, diferente daquela conhecida pelo pai: de uma militância e de família constituída.

Decerto que este não é o primeiro trabalho a analisar este romance. Muitos pesquisadores têm trabalhado sua escrita de variadas formas: Lehmen (2014) trata do "empresário da memória", quando destaca, apoiada em Elizabeth Jelin, a função criativa nos espaços não

3 As partes deste artigo são capítulos do romance de Bernardo Kucinski, aqui ressignificados. Este primeiro confronta os conceitos de abertura política, quando do período de redemocratização brasileira em meados dos anos 1980; a abertura, enquanto parte da obra de Bernardo Kucinski, quando Fleury toma voz e detalha as operações de desaparecimento e de tortura com os parentes; e abertura, enquanto introdução, um abre-portas para o trabalho e para a conceituação proposta.

Revista Vernáculo n. ${ }^{\circ} 42$ - segundo semestre /2018

ISSN 2317-4021 
compreendidos; Lira (2017), por sua vez, salienta as distinções do real e do fictício na premissa do trauma e, a partir disso, ressalta a aparente legalidade da Ditadura Civil-Militar brasileira, que se distingue dos outros regimes de exceção vividos na América Latina; SarmentoPantoja (2014) compara o romance de Kucinski com Soledad no Recife, de Urariano Mota, analisando as narrativas de resistência em sua construção histórica; Friedman e Bastazin (2016), destarte, discorrem acerca das funções da memória e da narrativa na Literatura de Testemunho - para tal, incluem na discussão os traumas (individuais e coletivos) que envolvem as histórias enredadas no romance em tela; Marques (2017) faz uma comparação entre as personagens em Kucinski e Kafka, ao mesmo tempo em que aproxima os contextos históricos presentes em $O$ Processo e K.: Relatos de uma busca.

Nessa narrativa, encontramos uma polifonia de vozes que discorrem acerca da busca dos algozes às testemunhas. São vozes de funcionários do Estado, o Delegado Fleury, a amante deste delegado, uma faxineira; em que todos colaboram para uma fratura exposta das violências promovidas e legitimadas pelo Governo brasileiro, e dos seres humanos afetados por este.

Uma dor irremediável essa da perda. Sobreviver enquanto o próximo morre ou é desaparecido. E como comunicar esta dor? Faz-se necessário muito mais que empatia. Provavelmente alguma interjeição tenha maior valor. Algo que não tenha representação consonantal. A fratura, esta condicionadora na tradução de uma linguagem indizível 
para o código, clama por algo mais de vitalidade, que fundadora alcance o âmago do ser que escreve. Pede por palavras que, concatenadas, desloquem-se da gramatura do papel e se fixem texturizadas no leitor.

Neste artigo me encarrego de uma análise do romance $K$.: Relatos de uma busca à vista do conceito de partilha de Jacques Ranciére, percebendo a saga de traumas e experiências-limite que marcam a família Kucinski. A partir deste ponto de vista, debulharemos as violências extrínsecas que permanecem conscientes na cabeça de Majer. Partilhados os comuns e entendidas as suas exclusividades, entende-se um "sistema de evidências sensíveis", na obra retratada pelo narrador-personagem, consciente, mas passivo.

Trata-se de uma narrativa do desaparecimento de Ana Rosa, a filha de Majer - um judeu sobrevivente da Shoah ${ }^{4}$. Em meio às diversas narrativas, todas elas aparentemente esparsas em suas individualidades, se imerge nessa busca e em suas personagens. Interlocutores loquazes, mergulhados cada um em seu sistema.

Para tal, divido o estudo em duas metades. Uma que se sente narrativa, pois vincula a obra na conceituação; outra dissertativa, constituinte de uma interpretação dos elementos testemunhais e da memória traumática. Visto assim, procura-se entender a obra às vistas das partilhas, compreendendo as razões da escrita e operação desta. O objetivo é, portanto, analisar a comunicação da memória para si e para

${ }^{4}$ Shoah é um segundo termo para o Holocausto, visto, porém, a partir de seu teor testemunhal, dos supertes e testis, bem como da memória coletiva dos judeus.

Revista Vernáculo n. ${ }^{\circ} 42$ - segundo semestre /2018

ISSN 2317-4021 
os outros, entendendo suas funções entre esquecimentos, silêncios e falas.

\section{Sobreviventes, uma reflexão ${ }^{5}$}

A violência, em K.: Relatos de uma busca, é uma conciliadora da trama. Ela perpassa a memória de todas as personagens; umas mais literais que outras. O caso a ser narrado é o do desaparecimento de Ana Rosa Kucinski em 1974, à época professora da Faculdade de Química da Universidade de São Paulo. O caso é mais um dos 388 mortos e desaparecidos no período entre 1964-1985, segundo o documento disponibilizado pelo Instituto Vladimir Herzog ${ }^{6}$. É esta violência corriqueira em um "sistema de evidências que revela, ao mesmo tempo, a existência de um comum e dos recortes que nele definem lugares e partes respectivas"7. Portanto, um comum e um lugar de disputa deste. Denomina, assim, Jacques Rancière o conceito de Partilha do Sensível.

Este comum é então visualizado de diversas maneiras. É ele "uma ordenação de signos". É, ainda, uma partilha que colabora e questiona ao mesmo tempo a memória dividida; é "a identificação dos

${ }^{5}$ Este título confronta, de novo, a obra com ressignificação proposta: "O sobrevivente só vive o presente por algum tempo; vencido o espanto de ter sobrevivido, superada a tarefa da retomada da vida normal, ressurgem com força inaudita os demônios do passado" (KUCINSKI, p. 154).

6 Disponível em: http://memoriasdaditadura.org.br/abertura-lenta-e-anistia-parcial/ (acesso em 16/05/2017). Este é um site "que responde à demanda da Secretaria de Direitos Humanos da Presidência da República de criação de um portal com o objetivo de divulgar a História do Brasil no período de 1964 à 1985 junto ao grande público, em especial à população jovem" (informação do próprio Instituto, disponível em: http://memoriasdaditadura.org.br/sobre-o-projeto).

${ }^{7}$ RANCIÉRE, 2005, p. 15.

Revista Vernáculo n. ${ }^{\circ} 42$ - segundo semestre $/ 2018$

ISSN 2317-4021 
modos de uma leitura dos signos escritos na configuração de um lugar, um grupo, um muro, uma roupa, um rosto". 8

Este conceito introduzido por Rancière, em $O$ Desentendimento: política e filosofia (1996) e melhor explorado em A Partilha do Sensivel: estética e política (2005), funciona aqui como condutor da perspectiva no estudo da obra de Kucinski. A partir deste ponto de vista percebem-se as relações memorialísticas do trauma, neste trabalho. E aqui é importante entender o porquê dessa preferência teórico-metodológica.

Se entende a partilha enquanto estética; realidade de comunidade entre um radicalismo artístico e outro político. O é, em primeiro ponto, por ser atributo da arte

operar um novo recorte do espaço material e simbólico. E é nesse ponto que a arte toca a política. A política, de fato, não é o exercício do poder, ou a luta pelo poder. É a configuração de um espaço específico, a partilha de uma esfera particular de experiência, de objetos colocados como comuns e originários de uma decisão comum, de sujeitos reconhecidos como capazes de designar esses objetos e argumentar a respeito deles. ${ }^{9}$

E em segundo, pela premissa de que "o real precisa ser ficcionado para ser pensado" ${ }^{10}$. Entende-se, portanto, um motivo fundador da arte, que, condicionador na tradução de uma linguagem indizível para o código, clama por algo mais de vitalidade, que,

${ }^{8}$ IDEM, p. 55.

${ }^{9}$ RANCIÈRE, 2010, p. 20.

${ }^{10}$ IDEM, p. 58.

Revista Vernáculo n. ${ }^{\circ} 42$ - segundo semestre /2018

ISSN 2317-4021 
fundadora, alcance ao âmago do ser que escreve. Por um lado político, por outro artístico; fundamentalmente estético.

Desta forma apresenta-se o autor na obra, anunciando-a: "Caro leitor: Tudo neste livro é invenção, mas quase tudo aconteceu". Funciona como um prenúncio ao leitor, como se dissesse que essas poderiam ser memórias, mas foram inventadas; ou mais, que ali se ausenta o escritor, o jornalista, o próprio Kucinski, para dar lugar ao narrador. Uma narrativa que mantém consciência e ação na voz presente, e se ramifica por vezes.

Presentes nas vozes do protagonista, do Delegado Fleury, da amante do Delegado, da faxineira que trabalhava para Fleury, de informantes, entre outros. Encontra-se o narrador coexistindo entre estas personagens, como se fosse mais uma, e, claro, outra voz no romance. Essas vozes polifônicas, multifacetadas, aparecem sem "chamados", capítulo a capítulo. Mostram-se confusas, propositalmente. Longe de um erro, mas uma característica perspicaz da narrativa que utiliza desta para partilhar a violência entre as personagens. Entretanto, isoladas cada qual em seu sistema. Como individualidades compartilhadas na narração, entendidas partes exclusivas, interseccionadas pelo desaparecimento de Ana Rosa Kucinski.

São partilhadas as violências sofridas na Shoah por Majer e a Ditadura civil-militar brasileira, como pode ser visto no excerto a seguir: 
K. tinha trinta anos quando foi arrastado pelas ruas de Wloclawek, acusado de subversão pela polícia polaca. Por isso emigrou, emigrou às pressas, deixando mulher $\mathrm{e}$ filho, que só se juntariam a ele no Brasil um ano depois. Foi solto na condição de emigrar, além da propina coletada pelos amigos de militância. Sua irmã, Guita, cinco anos mais velha, não tivera a mesma sorte. Morreu tuberculosa no frio da prisão.

A imagem repentina de Guita puxou a do delegado que o expulsara do topo da escadaria de Varsóvia aos gritos de que sua irmã nunca fora presa, de que teria fugido para Berlim, isso sim, com alguma amante.

Ainda pensava em Guita quando chegou ao general, que o recebeu de maus modos. Mandou-o sentar com rispidez. Reclamou que ele estava espalhando na comunidade judaica acusações pesadas e sem fundamento contra os militares. E se sua filha fugiu com algum amante para Buenos Aires? O senhor já pensou nisso? ${ }^{11}$

Os signos da ida à delegacia em busca de um parente e as consequentes respostas à visita são lugares de disputa na memória traumática da personagem. Uma ordenação de signos, que conflui para a divagação consciente sobre a leitura da cena. Bem, a linguagem é uma ordenação ou uma coordenação de consensos. A "linguagem está relacionada com coordenações de ação, mas não com qualquer coordenação de ação, apenas com coordenação de ações consensuais. Mais ainda, a linguagem é um operar em coordenações consensuais de coordenações consensuais de ações". ${ }^{12}$

$\mathrm{O}$ que se quer entendido aqui é a linguagem como inerente ao ser humano. São coordenações consensuais de conduta de coordenações consensuais de conduta. Em que se abstraem sentimentos fundamentais

${ }^{11}$ KUCINSKI, 2016, p. 37.

12 MATURANA, 1998, p. 20.

Revista Vernáculo n. ${ }^{\circ} 42$ - segundo semestre /2018

ISSN 2317-4021 
ao ser humano na forma do texto. A exemplo, uma pessoa mais velha pode ver um copo de café sobre a mesa de trabalho de um jovem qualquer e rememorar a sua mesa de trabalho que, comumente, apresentava o copo de café. Daí coordenar o código para que se faça compreensível àquela memória à pessoa jovem detentora do copo de café. Comunicam-se dessa forma, situações comunais aos envolvidos consensos. E a partir destas, concatenadas e coordenadas as palavras, o linguajar se faz consensual aos envolvidos. Reapresentam-se cenas.

Em K.: Relatos de uma busca, um trauma coexiste no outro consensualmente, disputando e sendo lugar comum. Kucinski aqui opera sobre e com a partilha: primeiro, entendendo sua função máxima de intersecção entre arte e política - sua ambivalência estética-política; segundo, confluir a violência, a partir de movimentos em diferentes temporalidades, em uma mesma perspectiva, a de testis $^{13}$ do acontecimento no protagonista. Essa segunda entendida na máxima função de testemunha em terceira pessoa; aquele que não atuou no fato, mas observou de longe, com envolvimento limitado.

A narrativa segue um fluxo que permeia o tema da busca de uma desaparecida política. Ao passo, as vozes mudam em diferentes tópicos da obra: ora o pai, ora o pai de Wilson, ora o Delegado Fleury,

${ }^{13} \mathrm{O}$ Testis é aquele que testemunha e atesta a experiência de terceiros. Em função jurídica, por um lado, essa atestação confere a necessidade de verificação do ocorrido por fonte confiável, seja ela humana ou não. Por outro lado, entendendo sua função à perspectiva psicanalista, a testemunha é portadora e dominada desta cena traumática, incapacitada de traduzir tal recordação e fragmentada ela própria. Ver em SELIGMANN-SILVA, Márcio. "Zeugnis" e "Testimonio": um caso de intraduzibilidade de conceitos. Revista Letras, n. 22, p. 121-130, 2001.

Revista Vernáculo n. ${ }^{\circ} 42$ - segundo semestre /2018

ISSN 2317-4021 
ora a faxineira da casa de torturas. Que corroboram para a construção do cenário de violências, dispostas de forma a compor um panteão de elocuções aparentemente desconexas, mas que compartilham de formas diferentes o desaparecimento.

A partilha ocorre aqui como um suporte memorialístico em que se percebem as diversas ribaltas a que o narrador expõe. Como quando se suplementam as memórias com invenções - imaginações, mesmo sobre a reunião da congregação do Conjunto das Químicas da Universidade de São Paulo, quando da demissão de Ana Rosa Kucinski por "abandono de função". Entende-se a posição imaginativa das atas de reunião, que bem se sabe, são tão inventadas quanto a obra aqui em questão. Percebe-se nesta situação os devaneios em que imerge o narrador para descrever com nitidez as cenas expropriadas das verdades inventadas. Valem mais ou menos? A questão, talvez, não passe por esta qualidade, mas com o pertencimento àquela memória, parafraseando Foucault: isto é uma ficção, mas quem escreveu não fui eu; inventada, mas plausível. Inventadas não porque não existiram, mas porque, simplesmente, é algo irrepresentável:

A ideia de uma narrativa impossível, mas absolutamente necessária (...), parece aplicar-se perfeitamente a esse sofrimento indizível posto em cena com o traumático e que torna tão fundamental, para aqueles que sobreviveram ao catastrófico do trauma, a paradoxal tarefa de narrar o intransmissível. Que falem por nós as palavras dos sobreviventes das grandes catástrofes históricas, que costumam relatar em seus testemunhos que seus relatos 
nunca conseguem transmitir realmente as experiências inenarráveis de horror pelas quais passaram. ${ }^{14}$

Seguem-se narrativas polifônicas conduzindo o interlocutor à busca da filha de Majer Kucinski. Emaranhados da mesma história compartilhando violências, cada qual à sua maneira. Funcionam aqui como suplementos ${ }^{15}$ das memórias catastróficas do pai, as quais preenchem lacunas já completas; ressignificam a memória para "uma zona imprevista". Como testemunha do desaparecimento da filha pelo Estado ditatorial brasileiro, esta memória e atestação "vale essencialmente por aquilo que nele falta; contém, no seu centro, algo intestemunhável, que destitui a autoridade dos sobreviventes". Preenche-se os vazios que deveriam estar completos, por não merecer existir. ${ }^{16}$ Se por um lado percebemos a situação do indivíduo que experimentou o trauma, por outro temos que perceber a condição que

${ }^{14}$ MALDONADO \& CARDOSO, 2009, p. 46-47.

15 Entende-se que "o suplemento é um extra desnecessário, adicionado a algo completo em si mesmo. Mas o suplemento é adicionado a completar e compensar uma lacuna, em algo que deveria ser completo em si mesmo" (DERRIDA, 1995, p. 243). Ou que "a lógica do suplemento é a lógica da não-identidade e da não-propriedade. (...) Sua lógica consiste mesmo em escapar sempre a esse dualismo marcado, à identidade, na medida em que pode ser o dentro e o fora, o mesmo e o outro: sua especificidade reside, pois, nesse "deslizamento" entre os extremos, na ausência total de uma essência" (SANTIAGO, 1976, p. 90).

${ }^{16} \mathrm{Se}$ entende aqui a validade do testemunho em sua forma jurídica e cultural, como descreve Primo Levi em É isto um homem?, em que a "verdade" das catástrofes nunca poderá ser entendida ou representada, visto que uma multidão anônima não pode contar a sua versão. Porque sucumbiram ao sorvedouro, à tortura e à opção dada: a de não ter opção. As histórias dos "muçulmanos", dos submersos, dessa massa populacional de não-homens que nunca poderá ser traduzida. As citações vêm de AGAMBEN, 2008, p. 43.

Revista Vernáculo n. ${ }^{\circ} 42$ - segundo semestre $/ 2018$

ISSN 2317-4021 
soterra essa individualidade, ao ponto de apresentar uma história oficial e coletiva, diferente desta subterrânea, como Pollak nos informa:

A fronteira entre o dizível e o indizível, o confessável e o inconfessável, separa, em nossos exemplos, uma memória coletiva subterrânea da sociedade civil dominada ou de grupos específicos, de uma memória coletiva organizada que resume a imagem que uma sociedade majoritária ou o Estado desejam passar e impor. ${ }^{17}$

\section{Um inventário de memórias ${ }^{18}$}

Com o projeto de educação musical, Heitor Villa-Lobos, maestro brasileiro, categoriza o músico de três formas: os que escrevem segundo regras e modas, os que tentam ser originais e os que escrevem por não conseguir viver sem ela. Este último teria maior valor, para o maestro. Seria ele o musicista interessado pelas tradições populares, entendedor dos sentimentos comuns. Conheceria, portanto, o ritmo daqueles e, a seu modo, apontaria as melodias e harmonias capazes de representar as sensações. ${ }^{19}$

A Valsa da Dor, de 1930, comporta uma das marcas do compositor, a da selvageria perante a harmonia. Nela, conforme a

${ }^{17}$ POLLAK, 1989, p. 8.

${ }^{18}$ Uma das perspectivas de análise deste trabalho é a de utilização megatextual, em que pontes intertextuais conectam constelações de conhecimentos. No caso deste trabalho, relacionamos o trauma relatado no romance de Bernardo Kucinski aos aspectos memorialísticos, à música de Villa-Lobos, aos deslizamentos do suplemento, às partilhas presentes no texto e à experiência humana. Vista sob a ótica de um livro, de uma obra musical, de um aspecto histórico, da construção deste aspecto e suas interpretações e de um estranhamento causado pela alteridade que é promovida pela verossimilhança.

${ }^{19}$ CONTIER, 1996, p. 110.

Revista Vernáculo n. ${ }^{\circ} 42$ - segundo semestre /2018

ISSN 2317-4021 
melodia desaba sobre o ritmo, a progressão de acordes descreve a melancolia que o autor sente, até que são cortadas por uma tensão, duvidosa daquela tristeza. Entretanto, volta a penúria e a música permanece em uma consonância taciturna.

Assim segue K., que durante a narrativa percorre prostrado a busca da filha desaparecida e que em algumas aparições a esperança é sustentada, como uma incerteza percussiva. Em Imunidades, um paradoxo, o narrador retrata a trilha que o pai atravessa. No começo "há esperança, não se pensa no impensável”, à medida em que o sumidouro cresce, o pai "ergue a voz"; angustiado, já não sussurra, aborda sem pudor os amigos, os amigos dos amigos e até desconhecidos", ao passo que "é tomado pelo cansaço e arrefece, mas não desiste. (...) Esperanças já não tem, mas não desiste". Descobre o silêncio gritante cativo de um sistema que atemoriza sem rosto. Ele, que rosto tem, mostra-o em passeatas, "nada o atemoriza", "não é mais um indivíduo, virou um símbolo, o ícone do pai de uma desaparecida política", ao passar dos anos o pai deixa "de ser um ícone. Já não é mais nada. É o tronco inútil de uma árvore seca". ${ }^{20}$

Villa-Lobos e Kucinski visam alcançar o âmago do espectador, até onde o mesmo aguentar. Partilham violências comunais aos seus contextos. De um lado a vontade de educar para civilizar, proposta vindoura da virada do século, do Estado Novo, o nacionalismo redentor; do outro a vontade de não esquecer, ou de memorar.

${ }^{20}$ KUCINSKI, p. 83-85.

Revista Vernáculo n. ${ }^{\circ} 42$ - segundo semestre /2018

ISSN 2317-4021 
$\mathrm{Na}$ experiência brasileira, dois momentos traumáticos confluem para a acepção de violência: a da colonização, escrita a sangue; e a da ditadura, não escrita - visto o ocultamento dos registros oficiais. Entender "a história como trauma coloca em questão a própria possibilidade de elaborar uma representação, pois o trauma é, por definição, algo que evitamos lembrar, evitamos reencontrar, pelo grau intolerável de dor que a ele se associa" 21 . Entender a história e a historiografia brasileira, portanto, sob essa ótica, altera a perspectiva com que rememoramos lugares, pessoas e símbolos, já que são entendidos os locais de fala de cada um, para uma via alternativa: uma em que as experiências silenciadas, as vidas "não-ditas", são ouvidas e relatadas em uma pluralidade de plataformas (jornais, revistas, artigos, livros, jogos, HQ's, fotografias, música, etc.).

Partilhar, na história, estes traumas é entender que estética e política estão imanentes uma à outra. E essa relação imbricada acaba por manter-nos em um meio consensual do qual não conseguirmos distinguir certas violências. Elas estão esquecidas. Neste ponto, poderíamos tomar como exemplos a institucionalidade do racismo ou, mesmo, a aceitação dominante do masculino e das masculinidades. Ambos estéticos e políticos, partilhados de forma consensual com a totalidade. Entendidas as violências como portadoras e fundadoras de suas histórias, entende-se, também, uma "novidade da tradição": formas novas de se adequar aos costumes violentos. Ou mesmo, complemento

${ }^{21}$ GINZBURG, 2011, p. 131.

Revista Vernáculo n. ${ }^{\circ} 42$ - segundo semestre /2018

ISSN 2317-4021 
do último, a "tradição da novidade": a força potencializadora de encontrar o novo. ${ }^{22}$

A arte, aqui representada no romance, compreende um regime poético fugidio do real. Não por disparidade, mas por verossimilhança, poética e mimética. Verossimilhança atestada segundo o testis em potência, o protagonista e sua busca, que não cessa enquanto não encontrar as suas verdades, a memória da filha desaparecida. Tem, então, sua tradição da novidade traduzida na culpa pelo desaparecimento. Que toma conta do cotidiano, da conjuntura e se transforma estruturalmente no tempo. A banalidade do mal, ou a naturalização deste, como construto da experiência coletiva, impressa nos jornais, em nomes de ruas e exposta pela imprensa, constrói um sistema de provocações e provações ao qual o protagonista percorre. A culpa perante esta naturalidade com que se tratam as violências e suas respostas. As da filha são olhares avulsos, nomes diferentes e um medo irrefreável de vida, minúcias triviais, detalhes que passam despercebidos pelo pai. A culpa recai sobre todas estas respostas e sobre a importância do iídiche ${ }^{23}$, a permanência dele neste mundo de traumas, entre tantos outros. A culpa de existir perante a inexistência do outro. A culpa nos porquês, "porque o sobrevivente vive o sentimento paradoxal da culpa da sobrevivência. A situação radicalmente outra, na qual todos

${ }^{22}$ RANCIÈRE, 2005, p. 27-44.

${ }^{23}$ Língua germânica das comunidades hebraicas. Majer Kucinski é escritor e crítico literário neste idioma.

Revista Vernáculo n. ${ }^{\circ} 42$ - segundo semestre $/ 2018$

ISSN 2317-4021 
deveriam morrer, constitui sua origem negativa. A indizibilidade do testemunho ganha com este aspecto um peso inaudito". ${ }^{24}$

A culpa. Sempre a culpa. A culpa de não ter percebido o medo em certo olhar. De ter agido de uma forma e não de outra. De não ter feito mais. A culpa de ter herdado sozinho os parcos bens do espólio dos pais, de ter ficado com os livros que eram do outro. De ter recebido a miserável indenização do Governo, mesmo sem a ter pedido. No fundo a culpa de ter sobrevivido. ${ }^{25}$

Esta culpa dos sobreviventes permeia as funções do personagem: memorialísticas e de atuação. A perda do outro e não a de si próprio, já não inédita ao passo da perda da irmã na Shoah, e que deve-se calcar e recalcar estas memórias de experiências-limite para que a vida continue a passar. Essa que, calejada, move o personagem em um grito silencioso de desespero e sofreguidão pelo fim.

A partir destas reflexões, vale perguntar: "qual o valor de todo o nosso patrimônio cultural, se a experiência não mais o vincula a nós?"26, pois, se confrontados com as experiências catastróficas, limites na vivência, não se compreende a humanidade nestas. Outro questionamento possível: como traduzir a memória dos traumas, violências e catástrofes em código compreensível a terceiros? Não se tem fórmula, mas, decerto, é necessário sempre mais que palavras, imagens ou notas musicais. Porque representação requer mais que memória. Requer vivência ou mais. Necessita vitalidade. O que quero

${ }^{24}$ SELIGMANN-SILVA, 2008, p. 75.

${ }^{25}$ KUCINSKI, 2014, p. 167.

${ }^{26}$ BENJAMIN, 1987, p. 114.

Revista Vernáculo n. ${ }^{\circ} 42$ - segundo semestre /2018

ISSN 2317-4021 
dizer com isso? Que é necessário "pensar o passado contra o presente, resistir a um presente, não para um retorno, mas 'a favor, isso espero, de um tempo futuro' (Nietzsche), ou seja, convertendo o passado em algo activo e presente, para que por fim surja algo novo, para que pensar, sempre, se produza no pensamento". ${ }^{27}$

\section{Considerações Finais}

Faz-se inescusável que essa, bem como as obras de Urariano Mota e Flávio Tavares ${ }^{28}$ na literatura, ou Maurício Toro Goya e Gustavo Germano ${ }^{29}$, em fotografias, exponha suas memórias para que se tornem públicas e partes das histórias nacionais. Não para uma mera exibição do horror, mas para uma catarse daquilo que já aconteceu mas não deveria; para amostras do Estado de Exceção em sua forma crua, identificando o asco que o foi. E daí se buscar, retomando o que disse anteriormente, pensar um passado oposto ao presente, ou seja: um presente ativo e responsável por um futuro antagônico a esse passado rememorado nas obras citadas.

São traduções das experiências inenarráveis. Descritas para se converter ou ressuscitar. Manifestações do ser humano que precisa testemunhar, pois a memória traumática que fora vivida em primeira ou qualquer outra pessoa não está no arrolamento das representações

${ }^{27}$ DELEUZE, 1986, p. 127.

${ }^{28}$ Autores de Soledad no Recife, K. - Relatos de uma Busca e Memórias do Esquecimento, respectivamente.

${ }^{29}$ Autores dos ensaios fotográficos Gólgota, caravana de la muerte e Ausências, respectivamente.

Revista Vernáculo n. ${ }^{\circ} 42$ - segundo semestre /2018

ISSN 2317-4021 
habituais do ser humano. Não constituem consenso, nem são de fácil compreensão empática, posto que são dores irreparáveis e indizíveis. Há de se entender a sua complexidade de transcrição ou representação, que só é inteligível àquele que tocou o âmago da morte, mas sobreviveu. $\mathrm{E}$ de alguma forma tenta viver.

\section{Referências:}

AGAMBEN, Giorgio. O que resta de Auschwitz: o arquivo e a testemunha. Tradução Selvino J. Assman. São Paulo: Boitempo, 2008.

BENJAMIN, Walter. Experiência e Pobreza. In: Obras escolhidas. v. 1. Magia e técnica, arte e política. Ensaios sobre literatura e história da cultura. São Paulo: Brasiliense, 1987, p. 114-119.

CONTIER, Arnaldo. Villa-Lobos: o selvagem da modernidade. Revista de História, São Paulo, n. 135, p. 101-119, 1996.

DELEUZE, Gilles. Foucault. Paris: Éditions de Minuit, 1986.

DE DECCA, Edgar Salvadori. As metáforas da Identidade em Raízes do Brasil. Varia Historia, v. 22, n. 36, p. 424-439, 2006.

FRIEDMAN, Iris e BASTAZIN, Vera. K. - Relato de uma busca, de Bernardo Kucinski: ausência de memória na Literatura de Testemunho. Arquivo Maaravi: Revista Digital de Estudos Judaicos da UFMG, Belo Horizonte, v. 10, n. 18, maio 2016.

GINZBURG, Jaime. Escritas da Tortura. Diálogos latinoamericanos, n. 3, p. 131-146, 2001.

HALBWACHS, Maurice. A memória coletiva. Trad. de Beatriz Sidou. São Paulo: Centauro, 2006.

KOSELLECK, Reinhart. Estratos del tiempo. Barcelona: Paidós, 2003. 
KUCINSKI, Bernardo. K.: Relatos de uma busca. São Paulo: Companhia das Letras, 2014.

LEHMEN, Leila. A memória como empresa: os empresários da memória em K., de Bernardo Kucinski. Nonada, v. 1, n. 22, 2014.

LEVI, Primo. É Isto um Homem?. Tradução: Luigi Del Re. Rio de Janeiro: Rocco, 1988.

LIRA, Raphaella. O trauma da ficção ou a ficção do trauma: uma leitura de K. relato de uma busca, de Bernardo Kucinski. Literatura e Autoritarismo, n. 18, p. 15-21, jan. 2017.

MALDONADO, Gabriela e CARDOSO, Maria. O Trauma psíquico e o paradoxo das narrativas impossíveis, mas necessárias. Psic. Clin., Rio de Janeiro, v. 21, n. 1, p.45-57, 2009.

MARQUES, Luciana Araujo. Ausência como presença; presença como ausência em K., de Kucinski. Literatura e Autoritarismo, n. 18, p. 5-13, jan. 2017.2 Disponível em: https://periodicos.ufsm.br/LA/article/viewFile/25566/14930. Acesso em: 18/02/17.

MATURANA, Humberto. Emoções e linguagem na educação e na política. Tradução: José Fernando Campos Fortes. Belo Horizonte: Ed. UFMG, 1998.

NIETZSCHE, Friedrich Wilhelm. Crepúsculo dos ídolos, ou, como se filosofa com o martelo. Tradução de Paulo César de Souza. São Paulo: Companhia das Letras, 2006.

POLLAK, Michael. Memória, esquecimento, silêncio. Tradução de Dora Rocha Flaksman. Estudos Históricos, Rio de Janeiro, v. 2, n. 3, 1989, p. 3-15.

RANCIÉRE, Jacques. A partilha do Sensível: estética e política. Tradução: Mônica Costa Neto. São Paulo: EXO experimental org.; $2^{a}$ 
Edição, 2009.

RANCIÉRE, Jacques. A estética como política. Devires, v. 7, n. 2, p. 14-36, 2010.

SANTIAGO, Silviano. Glossário de Derrida. Departamento de Letras da PUC/RJ, supervisão geral de Silviano Santiago. Rio de Janeiro: F. Alves, 1976.

SARMENTO-PANTOJA, Tânia. Soledad no Recife, de Urariano Mota $e \quad K$, de Bernardo Kucisnki: Romance histórico? Romance de testemunho? Documentário ficcional? Ou testemunho romanceado?. XIV ABRALIC Anais Eletrônicos. Disponível em: http://www.abralic.org.br/anais/arquivos/2014_1434481407.pdf. Acesso em: 15/02/17.

SELIGMANN-SILVA, Márcio. Narrar o Trauma. Psic. Clin., v. 20, n. 1, p. 65-82, 2008.

SELIGMANN-SILVA, Márcio. "Zeugnis" e "Testimonio": um caso de intraduzibilidade de conceitos. Revista Letras, n. 22, p. 121-130, 2001.

SCHOLLHAMMER, Karl Erik. A história natural da ditadura. Lua Nova, n. 96, p. 39-55, septiembre / diciembre 2015.

VILLA-LOBOS, Heitor. Guia Prático: estudo folclórico musical. São Paulo: Irmãos Vitale, 1941.

Recebido em 28/05/2017, aceito para publicação em 06/11/2017 